\title{
Conjecturas entre indivíduo empreendedor e capital psicológico
}

As características consideradas para o comportamento empreendedor e as capacidades psicológicas que formam o capital psicológico se imbricam em referências positivas. A área do empreendedorismo traz algumas controvérsias quando busca identificar características do indivíduo empreendedor, discriminando empreendedores de não empreendedores, por meio de atitudes empreendedoras, ações, comportamentos e também algumas competências distintivas, visto que para ser caracterizado como empreendedor é preciso ter algumas qualificações que o diferencie de outros profissionais. A psicologia positiva pode contribuir ao apresentar as capacidades positivas instituídas pelo capital psicológico positivo ou simplesmente pelo capital psicológico (PsyCap), que produz um estado de acréscimo psicológico positivo em que a pessoa predispõe-se a apresentar uma elevada confiança para despender o esforço necessário para ser bem sucedida em tarefas desafiantes, fazer atribuições positivas acerca dos acontecimentos que vão suceder no presente e no futuro, manifestar perseverança em relação aos objetivos definidos, e, quando necessário, mostrar-se capaz de redirecionar os meios para atingir os fins, além de revelar capacidade para recuperar de adversidades. Este artigo tem como objetivo trazer reflexões de possíveis convergências entre as características do indivíduo empreendedor e o construto do capital psicológico. Dessa forma, apresentamos alguns pontos fundamentais da literatura sobre indivíduo empreendedor e capital psicológico com o intuito de evidenciar especificidades dessas duas áreas. Ao final são exibidas que as capacidades psicológicas que formam o constructo do capital psicológico, autoeficácia, esperança, otimismo e resiliência apresentam pontos de aproximação com várias características que elegem um indivíduo como empreendedor, e aponta necessidades de estudos empíricos.

Palavras-chave: Comportamento organizacional positivo; Capital Psicológico; Indivíduo empreendedor; Comportamento empreendedor

\section{Conjectures between individual entrepreneur and psychological capital}

The characteristics considered for the entrepreneurial behavior and psychological capacities that form the psychological capital overlap in positive references. The entrepreneurship of the area brings some controversy when seeking to identify characteristics of the enterprising individual, discriminating entrepreneurs not entrepreneurs, through entrepreneurial attitudes, actions, behaviors and also some distinctive competencies, as to be characterized as an entrepreneur you have to have some qualifications that differentiate from other professionals. Positive psychology can contribute by presenting the positive capacities established by the positive psychological capital or simply the psychological capital (PsyCap), which produces a state of positive psychological increase when the person is predisposed to have a high confidence to expend the effort required to be successful in challenging tasks, make positive attributions about the events that will succeed now and in the future, show patience in relation to the defined objectives and, where necessary, prove able to redirect the means to achieve the purpose, and demonstrate the capability to recover from adversity. This article aims to bring reflections of possible convergences between the characteristics of the individual entrepreneur and the construct of psychological capital. Thus, we present some fundamental points of the literature on entrepreneurial individual and psychological capital in order to highlight specificities of these two areas. At the end are displayed in our view, reflections of certain perceived convergences between the two reference fields, ending with some considerations, and pointing needs of empirical studies.

Keywords: Positive organizational behavior; Psychological capital; Individual entrepreneur; Entrepreneurial behavior.

\section{Topic: Empreendedorismo}

Reviewed anonymously in the process of blind peer.

Luciano Gonçalves de Lima

Universidade Estadual do Paraná, Brasil

http://lattes.cnpq.br/2982913629558878

lucyanolima@yahoo.com.br

Vânia Maria Jorge Nassif

Universidade Nove de Julho, Brasil

http://lattes.cnpq.br/6936403740310206

vania.nassif@uol.com.br
Received: 17/01/2017

Approved: 18/03/2017
Referencing this:

LIMA, L. G.; NASSIF, V. M. J.. Conjecturas entre indivíduo empreendedor e capital psicológico. Revista Brasileira de Administração Científica, v.8, n.1, p.176-189, 2017. DOI: http://doi.org/10.6008/SPC2179-684X.2017.001.0014 


\section{INTRODUÇÃO}

Estudos desenvolvidos na área de empreendedorismo e comportamento organizacional positivo (COP) têm apresentado convergências importantes entre essas duas áreas. Pesquisa desenvolvida por Palma et al. (2007) evidencia que pontes estabelecidas entre o comportamento organizacional positivo e o empreendedorismo podem contribuir para o desenvolvimento mais sustentado de ambos os campos. Segundo os mesmos autores, o comportamento organizacional positivo pode colaborar com uma visão desenvolvimentista dos empreendedores, que facilite a sua caminhada ao longo das diferentes fases do empreendedorismo.

Buscando investigar essa contribuição, torna-se pertinente levantar reflexões sobre as capacidades psicológicas positivas de empreendedores, no que concerne ao otimismo, esperança, resiliência e a autoeficácia, variáveis que formam o construto do capital psicológico. A área do empreendedorismo traz algumas controvérsias, pelo fato de não ser entendido apenas através do desenvolvimento econômico e social, mas também sob a perspectiva da pessoa do empreendedor.

Assim, observamos a ausência de um consenso entre os teóricos, quer seja pela delimitação semântica ou mesmo conceitual (OGBOR, 2000; JULIEN, 2010), pelo caráter enigmático, multidisciplinar das pesquisas (FALCONE et al., 2005) ou ainda numa perspectiva dinâmica Bygrave (2004) destaca as diferentes características pessoais, psicológicas, sociológicas e ambientais. Sob esta vertente, o olhar se volta para identificar características do indivíduo empreendedor, diferenciando empreendedores de não empreendedores, por meio de atitudes empreendedoras, ações, comportamentos e também algumas competências distintivas, visto que para ser caracterizado como empreendedor é preciso ter algumas qualificações que o diferencie de outros profissionais, segundo o autor o processo empreendedor envolve todas as funções, atividades e ações associadas com a percepção de oportunidades e a criação de organizações para persegui-las (BYGRAVE, 2004).

Baron et al. (2011) aponta que a questão do reconhecimento da oportunidade é crucial no processo empreendedor, e que esse processo ocorre nas mentes de pessoas específicas, e que uma das variáveis que causa impacto nesse processo é percebida pela ação do próprio empreendedor, sobretudo quando age no nível individual, o que merece uma reflexão. Para Hisrich et al. (2009), os empreendedores pensam de modo diferente de outras pessoas, além de raciocinar diferente quando estão realizando outra atividade ou quando estão em ambiente de decisão. Hisrich et al. (2009) argumenta que não é raro observar empreendedores que tomam decisões em ambientes altamente inseguros, com altos riscos, intensas pressões de tempo e com estado emocional alterado.

Nessa linha de pensamento do empreendedorismo, que aborda o investimento emocional, a psicologia positiva pode contribuir ao apresentar as capacidades positivas instituídas pelo capital psicológico positivo ou simplesmente pelo capital psicológico (PsyCap), que produz um estado de acréscimo psicológico positivo em que a pessoa predispõe-se a: apresentar uma elevada confiança para despender o esforço necessário para ser bem sucedida em tarefas desafiantes; fazer atribuições positivas acerca dos acontecimentos que vão suceder no presente e no futuro; manifestar perseverança em relação aos objetivos 
definidos, e, quando necessário, mostrar-se capaz de redirecionar os meios para atingir os fins; e revelar capacidade para recuperar de adversidades (LUTHANS et al., 2007; LUTHANS et al., 2004).

Assim, diante destas reflexões este artigo teórico tem por objetivo trazer reflexões de possíveis convergências entre as características do indivíduo empreendedor e o construto do capital psicológico cujo intuito é o de abrir perspectivas para que pesquisadores dessa área possam desenvolver pesquisas empíricas, observando a existência de possíveis contribuições para a solidificação dos fenômenos.

O artigo está estruturado da seguinte forma: a primeira seção apresenta a revisão da literatura pertinente aos constructos a serem discutidos. A segunda seção traz uma reflexão entre indivíduo empreendedor e capital psicológico e finaliza com algumas considerações e apontando a necessidade de pesquisas empíricas sobre o tema abordado.

\section{REVISÃO TEÓRICA}

A revisão da literatura está ancorada em três áreas do conhecimento, compreendidas respectivamente, pelo comportamento organizacional positivo que busca expor a origem e as características dessa variável, seguida pelo capital psicológico que apresenta as capacidades positivas que compõem esse constructo. Finaliza com conceitos e particularidades que caracterizam o comportamento e o indivíduo empreendedor, apontando possíveis convergências entre os constructos apresentados. Buscando evidências sobre afinidade entre as áreas foi realizada uma busca junto à base de dados da Ebsco, Capes, Proquest procurando por estudos e pesquisas desenvolvidas nestes campos, que propiciaram investigar relações entre empreendedorismo e capital psicológico.

\section{Comportamento Organizacional Positivo (Cop)}

Pesquisas desenvolvidas por Seligman et al. (2000) aponta que o objetivo da psicologia positiva está em requerer uma mudança no foco da psicologia, alterando sua preocupação voltada apenas para eventos ruins da vida, visando construir qualidades positivas. É nesse enquadramento que se observa o surgimento de uma nova corrente dentro da psicologia intitulada como psicologia positiva, centrada nos estudos das forças, das virtudes e dos aspectos mais positivos da vida, com vista ao desenvolvimento da autorrealização e do significado de vida das pessoas já saudáveis e felizes.

Nesse pensamento, Luthans (2002a, 2002b) foi o responsável pela agregação de valor para a psicologia positiva organizacional, que, a partir da fundamentação do pensamento estabelecido por Seligman propõe a necessidade de uma verificação do comportamento organizacional positivo, estabelecendo uma relação, além do estilo popular de autoajuda, de variáveis que evidenciam o valor da psicologia positiva para as organizações. Assim, de acordo com Luthans (2002a,) o comportamento organizacional positivo é definido como "O estudo e aplicação dos pontos fortes, recursos humanos e capacidades psicológicas positivamente orientadas que podem ser medidas, desenvolvidas e geridas de forma eficaz para a melhoria do desempenho". 
Sob a perspectiva de Luthans et al. (2007), existem alguns critérios específicos para que uma capacidade psicológica possa ser concebida pelo comportamento organizacional positivo, de tal forma que deve abarcar certas condições como: ser positivamente orientada, ser baseada na teoria e na investigação, ser mensurável, ser suscetível de desenvolvimento e melhoria, além de ter um impacto demonstrado na melhoria do desempenho no contexto organizacional. Buscando clarificar esses critérios, que são de grande importância para o entendimento do comportamento organizacional positivo, o quadro 1 apresenta esses conceitos a partir de seus critérios e as descrições decorrentes deles.

Quadro 1: Critérios do Comportamento Organizacional Positivo (COP).

\begin{tabular}{|c|c|}
\hline Critérios & Descrição \\
\hline Ser positivamente orientada & $\begin{array}{l}\text { A capacidade psicológica tem de ter natureza positiva (de acordo com as definições existentes } \\
\text { na literatura da Psicologia Positiva). Procura-se com este critério reconhecer e enfatizar o } \\
\text { poder que a positividade pode ter no contexto organizacional. }\end{array}$ \\
\hline $\begin{array}{c}\text { Ser baseada na teoria e na } \\
\text { investigação }\end{array}$ & $\begin{array}{l}\text { O COP compromete-se com uma abordagem científica para inclusão e acumulação de um corpo } \\
\text { de conhecimento sustentável com impacto para a liderança, para o desenvolvimento dos } \\
\text { recursos humanos e para o desempenho. A inclusão deste critério permite assegurar que se está } \\
\text { a trabalhar numa teoria que contribui ao longo do tempo para o crescimento sustentável e } \\
\text { melhoria do desempenho das organizações. }\end{array}$ \\
\hline Ser mensi & $\begin{array}{l}\text { A questão da medição sempre foi o ponto central da investigação e aplicação, científica de } \\
\text { qualquer teoria. Para ter inclusão no COP, é necessário que existam instrumentos válidos e } \\
\text { viáveis de medição da capacidade psicológica em questão. }\end{array}$ \\
\hline $\begin{array}{c}\text { Ser suscetível de } \\
\text { desenvolvimento e melhoria }\end{array}$ & $\begin{array}{l}\text { O movimento da Psicologia Positiva está repleto de traços de caráter e virtudes que têm impacto } \\
\text { demonstrado no desempenho organizacional. Mas estes traços de personalidade tendem a } \\
\text { exibir uma estabilidade considerável ao longo do tempo, o que torna difícil o seu } \\
\text { desenvolvimento. O que se propõe com este critério e a inclusão de estados (não traços) de } \\
\text { personalidade maleável, suscetível de desenvolvimento e melhoria. Este critério é apontado } \\
\text { como fator diferenciador desta abordagem em face de um conjunto de concepções positiva } \\
\text { existentes no domínio do comportamento organizacional. }\end{array}$ \\
\hline $\begin{array}{l}\text { Ter um impacto demonstrado } \\
\text { na melhoria do desempenho } \\
\text { no contexto organizacional }\end{array}$ & $\begin{array}{l}\text { É fundamental que a capacidade psicológica tenha claro e significativo impacto no } \\
\text { desempenho dos indivíduos no contexto organizacional. Tendo em conta que nesta teoria } \\
\text { apenas devem ser incluídas capacidades psicológicas suscetíveis de melhoria e } \\
\text { desenvolvimento, tais capacidades podem ser geridas de forma a ter impacto positivo no } \\
\text { desempenho dos indivíduos em contexto organizacional. }\end{array}$ \\
\hline
\end{tabular}

Fonte: Luthans et al. (2007).

Para que uma capacidade psicológica possa ser incluída na concepção do comportamento organizacional positivo definida por Luthans é necessário que se verifiquem os critérios apresentados no quadro 1. Inicialmente, para melhor traduzir a operacionalidade definida pelos critérios, foram identificadas capacidades psicológicas como a autoconfiança (ou autoeficácia), a esperança, o bem-estar subjetivo (ou felicidade), a resiliência e a inteligência emocional como estado que preenchem os critérios do comportamento organizacional positivo (LUTHANS et al., 2005). Subsequentemente, a construção teórica, pesquisas e aplicações da teoria do comportamento organizacional positivo focaram-se apenas em quatro capacidades psicológicas que formam o construto do capital psicológico e que serão apresentados e explicitados no próximo tópico.

\section{Capital Psicológico}

O capital psicológico é um constructo constituído por quatro capacidades psicológicas. Assim, o capital psicológico positivo ou simplesmente, capital psicológico (PsyCap), produz um estado de acréscimo psicológico positivo em que a pessoa assinala-se por: apresentar uma elevada confiança para despender o esforço necessário para ser bem sucedida em tarefas desafiantes, fazer atribuições positivas acerca dos 
acontecimentos que vão suceder no presente e no futuro, manifestar perseverança em relação aos objetivos definidos, e, quando necessário, mostrar-se capaz de redirecionar os meios para atingir os fins e, revelar capacidade para recuperar de adversidades (LUTHANS et al., 2007; LUTHANS et al., 2004).

Assim de acordo com as capacidades psicológica descritas acima o capital psicológico abrange quatro competências distintas: autoeficácia, otimismo, esperança e resiliência, que segundo a construção teórica estas quatro capacidades psicológicas são as que melhor cumpriam os critérios do COP (LUTHANS et al., 2007). Dessa forma, os autores esclarecem que as pessoas possuidoras de uma combinação saudável dessas quatro capacidades acreditam que podem enfrentar tarefas difíceis e que situações desafiadoras terão uma solução favorável, por serem persistentes e facilmente mudam de direção para conseguir seus objetivos. Além disso, são capazes de tentar novamente para alcançar sucesso, mesmo diante da adversidade. De um modo simples, os autores indicam que o PsyCap está relacionado com "quem somos" e "quem nos tornamos em termos de desenvolvimento positivo". A Figura 1 apresenta o capital psicológico positivo e as quatro dimensões que formam esse construto, apesar do construto ser unidimensional.

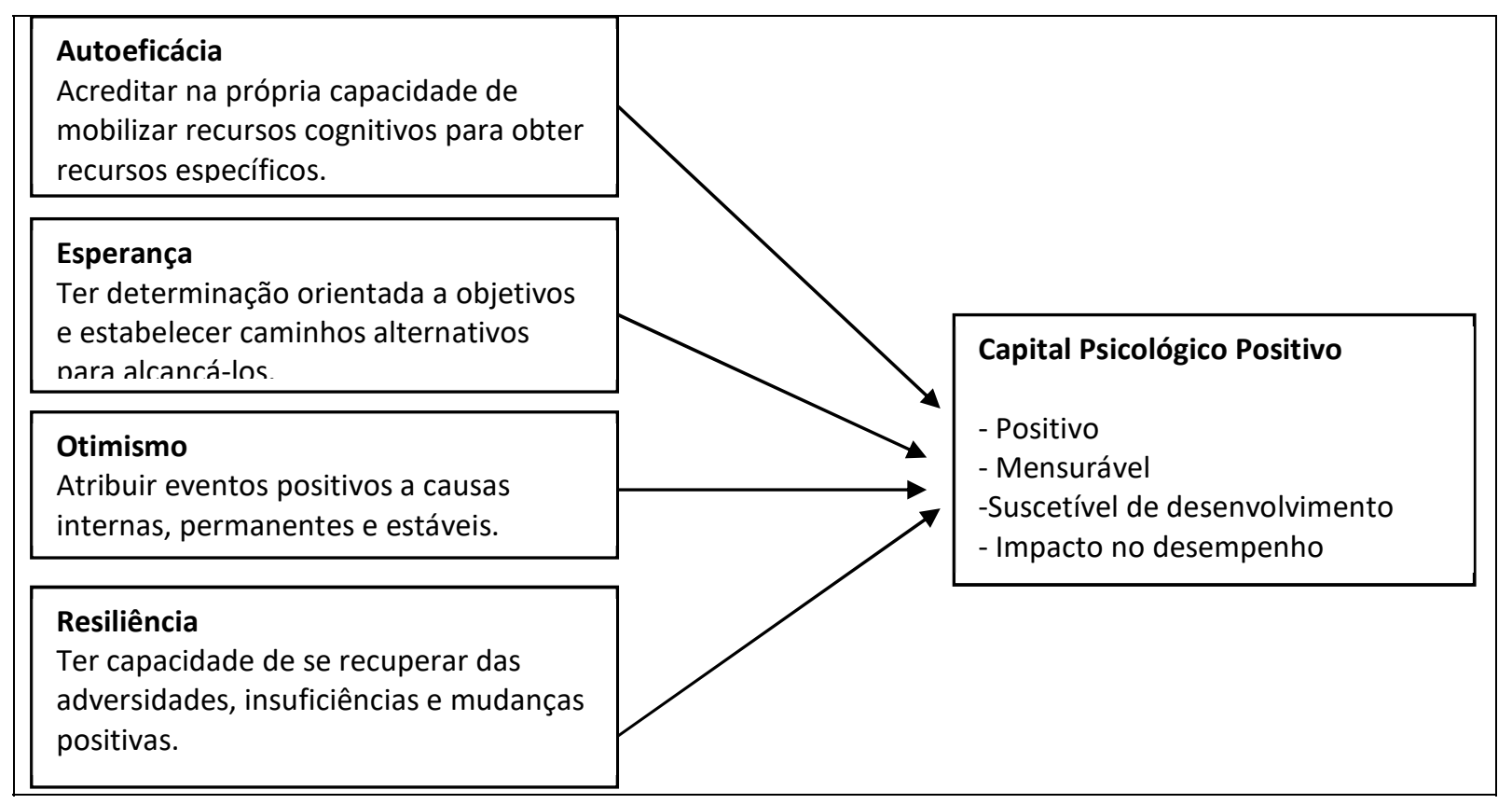

Figura 1: Dimensões do Capital Psicológico Positivo. Fonte: Page et al. (2004).

De acordo com a figura 1, o capital psicológico positivo ou PsyCap constitui um construto de ordem superior que inclui capacidades psicológicas positivas centrais. A seguir será apresentada a definição dos quatro construtos que compõe o PsyCap, visto a necessidade de se ter uma teoria bem fundamentada para o melhor entendimento dos conceitos.

A autoeficácia é definida no modelo do capital psicológico segundo Luthans et al. (2004) como a confiança de se acreditar na própria capacidade de mobilizar recursos cognitivos para obter recursos específicos. Convergindo com esse conceito, Bandura (1997) definiu a autoeficácia percebida como "crenças nas capacidades do indivíduo para organizar e executar o curso de ação necessária para produzir algo".

Pessoas que são autoeficazes (autoconfiantes) primam por tarefas desafiadoras, estendendo motivação e esforço no cumprimento de seus objetivos, principalmente quando confrontados com obstáculos (Luthans et al., 2004). Ainda nessa mesma perspectiva, Bandura, (1997) e Stajkovic et al. (1998) apresentam como convicção aquilo que uma 
pessoa detém, relativamente à sua capacidade para mobilizar a motivação, os recursos cognitivos e os cursos de ação necessários para realizar com êxito uma tarefa específica num dado contexto. Pode-se concluir, assim, que a autoeficácia oferece benefício ao indivíduo, abertura para enfrentar os desafios, e uma vontade de despender um esforço na busca de um resultado de sucesso (PAGE et al., 2004).

O conceito de esperança tal como esclarece Luthans (2002a), no contexto da Psicologia Positiva, e mais precisamente da teoria do capital psicológico, adquire um significado específico. Segundo Luthans et al. (2007), no âmbito do capital psicológico a definição de esperança é desenhada a partir do trabalho de Snyder (2002), que sustenta a ideia de que a esperança é um estado cognitivo ou de pensamento através do qual um indivíduo é capaz de estabelecer expectativas e objetivos estimulantes, mas realistas, e procurar atingi-los através da sua autodeterminação, energia e percepção de controle interno.

Para além disso, Snyder (2002) considera ainda que, apesar de muitas vezes negligenciada na utilização comum do termo, outro componente da definição de esperança é o fato de as pessoas serem capazes de gerar caminhos alternativos para os objetivos que determinaram, quando surgem obstáculos ou impedimentos aos inicialmente traçados. É precisamente este componente que distingue a esperança entendida no âmbito do capital psicológico, da utilização diária e comum do termo. De acordo com a perspectiva de Snyder (2002), a esperança é assim um estado motivacional positivo baseado num sentido de sucesso resultante da interação de dois fatores: energia direcionada a determinados objetivos (designada por força de vontade ou agêncy) e planos para alcançar esses objetivos (waypower ou caminhos).

A esperança é, assim, abarcada pela determinação individual para desenhar e manter as energias necessárias com vista a atingir os objetivos delineados e pela habilidade em distinguir as ações alternativas para alcançar esses objetivos (LUTHANS et al., 2005). O otimismo, conforme Lopes et al. (2006) pode ser definido como uma crença generalizada que boas coisas acontecem no futuro. Luthans (2002b) define as pessoas otimistas como perseverantes perante obstáculos, satisfeitas, possuem elevado nível de ambição, determinam objetivos ambiciosos, além de serem facilmente motivadas ao trabalho, e ainda o defende como o conceito base do capital psicológico positivo. Contudo, para o PsyCap, o otimismo é mais do que prever que coisas boas vão acontecer.

Segundo Luthans et al. (2007), a distinção entre otimismo e pessimismo, no âmbito do PsyCap, está nas razões e atribuições que cada um faz para explicar o porquê de determinados eventos, sejam eles positivos ou negativos, passado, presente ou futuro. A distinção entre otimismo, no âmbito do PsyCap, e a utilização diária do termo reside assim na forma como os indivíduos interpretam e explicam as causas de acontecimentos positivos e negativos (LOPES et al., 2006).

A resiliência é definida pela American Psychological Association como o "processo e resultado de se adaptar com sucesso a experiências de vida difíceis ou desafiadoras, especialmente através da flexibilidade mental, emocional e comportamental e ajustamento a demandas externas e internas" (APA, 2010). A resiliência definida no modelo do capital psicológico possui uma maior abrangência, apontada por Luthans et al. (2007) como a capacidade de recuperação perante situações de adversidades, mas também perante eventos estimulantes indo além do esperado. Os pensamentos de Luthans (2002a) e de Luthans et al. (2004) complementam este raciocínio ao atestar que indivíduos resilientes são portadores da capacidade de recuperação/superação da adversidade, incerteza, falha, e até mesmo da mudança positiva com tarefas que acarretam maior responsabilidade.

Na psicologia, a resiliência é utilizada para explicar superação de crises e adversidades em indivíduos, grupos e organizações. Luthans et al. (2004) afirmam que a resiliência pode ser desenvolvida em nível individual. Por outro lado, Sabbag (2012) a define como competência de indivíduos que se fortalecem, ao permitirem enfrentar e até aprender 
com adversidades e desafios. É uma competência porque pode ser aprimorada: reúne consciência, atitudes e habilidades ativadas nos processos de enfrentamento de situações em todos os campos da vida.

\section{Indivíduo, Comportamento Empreendedor e Capital Psicológico}

O comportamento empreendedor obteve os primeiros estudos centrados nas características e nas variáveis de personalidade, demográficas e culturais. Dentro do campo da psicologia, McClelland (1965) foi um dos precursores ao considerar a necessidade de realização como a característica mais distintiva da motivação para a realização. Para este autor, a autorrealização é uma das características psicológica que fornece condições às pessoas de escolherem e persistirem em atividades que envolvem um padrão de excelência e/ou em tarefas desafiadoras. Em outro trabalho, McClelland (1986), introduz, ainda, entre as características de necessidade de realização, a iniciativa, a afirmação, a orientação para eficiência, o planejamento sistemático e o comprometimento com o trabalho.

Um indivíduo empreendedor é caracterizado pelo conjunto de ações inovadoras e transformadoras em qualquer atividade humana. Destaca-se pelo fato de romper com os modelos tradicionais e de criar novos modelos, novos processos e demais inovações. Hisrich et al. (2009) argumenta que empreendedores pensam de forma diferente das outras pessoas, uma vez que podem, em determinada situação, raciocinar de modo diverso quando realizam outra atividade ou quando estão em uma situação de decisão.

Hisrich et al. (2009) aponta que é frequente os empreendedores tomarem decisões em ambientes altamente inseguros, com altos riscos, intensas pressões de tempo e considerável investimento emocional. E que, às vezes, no contexto destas situações o mesmo precisa executar e se adaptar de modo cognitivo, bem como aprender com o fracasso. A abordagem psicológica behaviorista ou comportamental, representada por autores como McClelland (1972), procura identificar aspectos característicos dos empreendedores, por acreditar que existem traços de personalidade que são próprios destes indivíduos (VRIES, 1997). Weber (1989) vê os empreendedores como inovadores, pessoas independentes, cujo papel de liderança nos negócios infere ser uma fonte de autoridade formal.

Por sua vez, Filion (1999) o define como "uma pessoa criativa, marcada pela capacidade de estabelecer e atingir objetivos e que mantém alto nível de consciência do ambiente em que vive, usando-a para detectar oportunidades de negócios". Filion (1999) relata algumas características dos empreendedores, como, por exemplo, o fato de terem sonhos realistas, ou visões, cuja realização pode ficar comprometida. Pontua, ainda, que os empreendedores gastam tempo imaginando aonde querem chegar e como chegar. E, por fim, delegam e treinam seus empregados para lidar com o inesperado. Estudiosos no assunto elaboraram uma relação de características para explicar quem é o empreendedor, e como ele pode ser reconhecido.

Embora a literatura recente pontue que não apenas características são passíveis de revelar quem é esse ator social, mas também por sua ação (JULIEN, 2010), ainda assim, é recorrente identificar o empreendedor por suas caraterísticas. Algumas delas, por exemplo, são entendidas por eles serem vistos como visionários e que sabem tomar decisões (BARON et al. 2007); fazem a diferença e exploram ao máximo as oportunidades (SHANE et al., 2000); são determinados, dinâmicos, dedicados, otimistas e apaixonados 
pelo que fazem (JULIEN, 2010; BRANCHER et al., 2012; BRUSH, 2002); independentes e procuram construir seu próprio destino (BRUYAT et al., 2001; BYGRAVE, 2004); organizados, líderes e formadores de equipe e bem relacionados (KIRZNER, 1973); possuem conhecimento, assumem riscos calculados, criam valor para a sociedade e planejam muito (BHIDÉ, 2004).

Tantas características necessárias ao empreendedor de sucesso geram um questionamento relacionado ao seu desenvolvimento: se ele nasce com estas características ou se as aprende com o tempo. Existe grande debate a respeito, com perspectivas e considerações bem diferentes (MORRISON, 1998). Em uma das abordagens, a característica empreendedora é apresentada como nata, isto é, pressupõe que a capacidade empreendedora, a habilidade para correr riscos e o desejo de criar um negócio são próprias do indivíduo, ou seja, o empreendedor nasce com estas características. Isto pode ser exibido na forma de traços de personalidade que diferenciam os empreendedores dos demais.

Alguns exemplos de traços genéticos associados ao empreendedorismo são: autoconfiança, motivação pessoal, criatividade, independência, liderança, propensão a correr riscos (HONMA, 2007). Esta abordagem não foi suficiente para sustentar os pressupostos que estudam o empreendedor. 0 empreendedorismo ainda pode ser cultural e experiencialmente adquirido e a capacidade empreendedora pode ser influenciada por intervenções da educação e de treinamento (GARAVAN et al., 1994). Filion (1999), Bohnenberger et al. (2007), e Bygrave (2004) concordam no que diz respeito à influência da família no perfil empreendedor e, consequentemente, na criação de novas empresas porque, para eles, as pessoas apresentam mais chances de se tornarem empreendedoras se houver um modelo na família ou no seu meio.

O empreendedor tem como característica básica o espírito criativo e pesquisador. Ele está constantemente buscando novos caminhos e novas soluções. O pensamento criativo para Oech (1995) supõe uma atitude, uma perspectiva que o leva à procura de ideias, como também à manipulação de conhecimentos e experiências. O indivíduo, ao adotar uma perspectiva criativa, tanto se abre para novas possibilidades como para mudança. Na linha da criatividade caminha a inovação. O processo de criatividade inspira a constante inovação para os empreendedores. A inovação, segundo Drucker (1986) "é o instrumento específico dos empreendedores, o meio pelo qual eles exploram a mudança como uma oportunidade". Filion (1999) corrobora esse pressuposto ao entender que um empreendedor é uma pessoa imaginativa distinguida pela capacidade de estabelecer e alcançar objetivos.

$\mathrm{Na}$ busca de entendimento para aspectos característicos dos empreendedores, a autoeficácia tem sido e continua a ser uma variável psicológica fundamental no estudo do comportamento empreendedor, tanto em seu poder preditivo sobre a intenção de criar uma nova empresa (BOYD et al., 1994; LINAN et al., 2009; PIHIE, 2009; ZHAO et al., 2005) e sua capacidade de diferenciar entre os empreendedores e não empreendedores (MARKMAN et al., 2005).

Buscando evidências que relaciona o campo do empreendedorismo com o comportamento organizacional positivo, cuja finalidade é a de explorar aspectos convergentes entre as características e/ou comportamento empreendedor com as variáveis que formam o capital psicológico, realizamos um levantamento junto à base de dados da EBSCO, CAPES e PROQUEST, utilizando palavras-chave mescladas 
como: empreendedor / capital psicológico, empreendedorismo / capital psicológico, empreendedorismo / psicologia positiva, empreendedorismo / comportamento organizacional positivo, entre outras combinações dos termos. A busca foi realizada tanto no idioma Português como no idioma Inglês o que resultou em estudos apenas no contexto internacional, conforme apresentado no quadro 2.

Quadro 2: Estudos que relacionaram Empreendedorismo e Comportamento Organizacional Positivo.

\begin{tabular}{|c|l|}
\hline Autor/Ano & \multicolumn{1}{c|}{ Título do Estudo } \\
\hline ZHAO et al. (2005). & O papel mediador da autoeficácia no desenvolvimento de intenções empreendedoras. \\
\hline $\begin{array}{c}\text { MARKMAN et al. } \\
\text { (2005). }\end{array}$ & $\begin{array}{l}\text { São perseverantes e autoeficazes sem custo? Avaliando o raciocínio e arrependimento dos } \\
\text { empreendedores. }\end{array}$ \\
\hline JENSEN et al. (2006). & Relação entre capital psicológico de empreendedores e sua liderança autentica. \\
\hline PALMA et al. (2007). & Comportamento Organizacional Positivo Empreendedorismo: Uma Influência Mutuamente Vantajosa. \\
\hline $\begin{array}{c}\text { IZQUIERDO et al. } \\
\text { (2008). }\end{array}$ & $\begin{array}{l}\text { Modelos concorrentes das intenções empreendedoras: influência da autoeficácia empreendedora e } \\
\text { atitudes. }\end{array}$ \\
\hline JAMES et al. (2011). & Explorando o impacto do otimismo empreendedor e o processo de criação de novas empresas. \\
\hline HAYEK et al. (2012). & $\begin{array}{l}\text { Crenças de controle e capital psicológico positivo. Pode empreendedores nascentes discernir entre o } \\
\text { que pode e não pode ser controlado? }\end{array}$ \\
\hline $\begin{array}{c}\text { TORRES et al. } \\
\text { (2013). }\end{array}$ & $\begin{array}{l}\text { Um exame da relação da autoeficácia gerencial para intenção empreendedora e performance das } \\
\text { pequenas empresas no México. }\end{array}$ \\
\hline
\end{tabular}

O quadro 2 traz estudos que relacionaram o empreendedorismo com constructos que compõe o campo de estudos da psicologia positiva, do comportamento organizacional positivo e do capital psicológico. Estes estudos investigaram as relações entre variáveis com vistas a trazer contribuições que fortaleçam o entendimento sobre empreendedorismo.

Estudo desenvolvido por Zhao et al. (2005) objetivou investigar o papel mediador da autoeficácia no desenvolvimento de intenções empreendedoras. Os autores utilizaram modelagem de equações estruturais com uma amostra de 265 professores de administração de empresas em cinco universidades. Os resultados mostraram que os efeitos da aprendizagem percebida de cursos relacionados com o empreendedorismo, experiência empreendedora anterior, propensão ao risco e intenções empreendedoras foram totalmente mediadas por autoeficácia empreendedora.

Markman et al. (2005) investigou a perseverança e a autoeficácia no desenvolvimento de novos negócios visando verificar se empreendedores e não empreendedores se diferem em tais atributos. Além disso, se altos níveis de perseverança e autoeficácia ajudam empreendedores a superar contratempos, empecilhos e obstáculos. 0 estudo utilizou uma amostra aleatória de 217 inventores de patentes na indústria de dispositivos médicos (cirurgia) para abordar as questões. Os resultados indicaram que os empreendedores apresentaram uma pontuação significativamente maior na autoeficácia e em não empreendedores.

Estudo desenvolvido por Jensen et al. (2006) analisou a relação entre capital psicológico e auto percepção de autêntica liderança. Utilizou uma amostra de 76 fundadores de negócios de pequenas organizações relativamente novas. Os resultados apontaram um impacto positivo na relação entre capital psicológico de empreendedores e auto percepção da autêntica liderança, exaltando que o capital psicológico se mostrou preditor na relação entre as variáveis. Em particular, os resultados iniciais também assinalaram que uma maior atenção seja dada às forças psicológicas e liderança autêntica que podem permitir aos empreendedores, não só sobreviver, mas prosperar dentro de um ambiente de desafio. 
Com base no levantamento realizado nas duas áreas, o estudo de Palma et al. (2007) procurou estabelecer sinergia entre o comportamento organizacional positivo e o empreendedorismo, de modo a contribuir para um desenvolvimento mais sustentado de ambas as disciplinas. Por influência da literatura sobre empreendedorismo, o comportamento organizacional positivo pode beneficiar-se com a introdução de uma maior preocupação com o impacto societal, de uma abordagem integrada e de uma perspectiva temporal no estudo das capacidades psicológicas.

A investigação sobre empreendedorismo pode ficar mais favorecida ao evidenciar o uso de critérios de êxito mais claros, a preocupação com o rigor metodológico e a utilidade de uma visão desenvolvimentista dos empreendedores, todas elas evidenciadas nos estudos do comportamento organizacional positivo. Izquierdo et al. (2008) desenvolveu estudo que testou dois modelos, explicando como educação para o empreendedorismo pode ter um efeito nas intenções empreendedoras através do impacto sobre atitudes e autoeficácia. Os dados foram coletados a partir de 236 estudantes que foram expostos a um curso de empreendedorismo. Enquanto no modelo 1 atitudes e autoeficácia são positivamente relacionados com intenções de criação de novas empresas, no modelo 2 atitudes mediou entre autoeficácia e intenções empreendedoras. Os resultados indicaram que as atitudes têm uma relação mais forte com intenções empreendedoras no modelo 2.

Por meio da integração de duas abordagens teóricas na pesquisa sobre empreendedorismo, a psicologia do empreendedor e o processo do empreendedorismo, James et al. (2011) propõe, no seu estudo, um novo modelo conceitual examinando comportamento empreendedor e emoção através do processo de desenvolvimento do novo empreendimento. A investigação existente numa visão macro do processo de criação de um novo empreendimento reconhece o empreendedor como um agente central no processo, contudo geralmente ainda evita, em cada fase do processo, um exame das experiências psicológicas de nível micro do empreendedor individual.

Da mesma forma, a pesquisa que examina as diferenças individuais comportamentais do empreendedor individual tem negligenciado a explorar sistematicamente a emoção e o comportamento do empreendedor em todo o ciclo do processo de criação do novo empreendimento. Os autores propõem uma estrutura conceitual que integra a fase de exploração do processo de criação do novo empreendimento com o otimismo, elemento do capital psicológico e comportamento do empreendedor individual.

Para Hayek (2012), os empreendedores foram retratados, numa perspectiva positiva, como sendo sonhadores, identificadores de oportunidade, resilientes, otimistas e autoconfiantes. A tentativa de compreender a lente através da qual empreendedor emergente aproxima ou percebe oportunidades é uma pedra angular da pesquisa sobre empreendedorismo, acarretando em implicações práticas significativas. Um passo importante na compreensão de como os empreendedores emergentes percebem oportunidades é através da compreensão de sua percepção de controle sobre seu ambiente. Embora as variáveis que formam o constructo capital psicológico, esperança, resiliência, otimismo e autoeficácia serem todas características reverenciadas e altamente associadas com os empreendedores, são necessários despender atenção às consequências destas se aplicadas a situações em que o indivíduo tem um senso deslocado de controle. 
O estudo de Torres et al. (2013) amplia a investigação sobre a relação entre autoeficácia, desempenho e intenção empreendedora. Chen et al. (1998), citado por Torres et al. (2013), propôs um constructo para predizer a probabilidade de o indivíduo ser empreendedor, testado em amostras paralelas de estudantes, proprietários e executivos de pequenas empresas. O constructo consiste de cinco fatores: mercado, inovação, assumir riscos e controle financeiro. $O$ estudo pretendeu validar o referido constructo com uma amostra de pequenas empresas de uma pequena cidade do centro oeste do México. Os resultados apontaram convergência em três fatores que parecem estar relacionados com a dificuldade ou a complexidade da tarefa. Tais fatores oferecem uma explicação do desempenho percebido do negócio, assim como as intenções empreendedoras dos proprietários e gerentes das empresas.

Através desses estudos relatados ficou evidente que as pesquisas no campo do empreendedorismo têm procurado fazer relações entre diferentes variáveis cujo intuito é o de propiciar maiores entendimentos que auxiliem tanto na solidificação do processo empreendedor como o de clarear aspectos relacionados ao comportamento que caracteriza um indivíduo como empreendedor. As capacidades psicológicas positivas que formam o capital psicológico são mencionadas na maioria dos trabalhos evidenciando um caminho a ser investigado com maior profundidade.

\section{RESULTADOS E DISCUSSÃO}

As pesquisas e reflexões aqui discutidas evidenciam que há muito ainda a ser pesquisado, quando os objetos de estudo recaem na arena do empreendedorismo relacionada com as características de pessoas vistas como empreendedoras. Tais reflexões trazem inquietações também relacionamos o comportamento organizacional positivo com as capacidades positivas que compõem o capital psicológico.

Se por um lado o empreendedor apresenta características distintivas como inovador, independente, hábil para liderar, criativo, capaz de estabelecer e atingir objetivos, detector de oportunidades, dentre outras, o capital psicológico positivo aponta que a combinação das quatro capacidades positivas é saudável e contributiva para as ações empreendedoras. Isso sugere que os constructos do capital psicológico são fatores que o empreendedor pode contar ao enfrentar tarefas difíceis e em situações desafiadoras, além de serem passíveis de soluções favoráveis. Assim, são reconhecidos como persistentes e capazes de mudar a direção de suas ações para conquistar seus objetivos mesmo diante de situações adversas.

Complementar a esses pressupostos, McClelland (1986) introduz no comportamento empreendedor as características de necessidade de realização, iniciativa, afirmação, orientação para eficiência, planejamento sistemático e o comprometimento com o trabalho. Luthans et al. (2007), no âmbito do capital psicológico, aponta que a esperança é um estado cognitivo ou de pensamento através do qual um indivíduo é capaz de estabelecer expectativas e objetivos estimulantes, mas realistas, e procurar atingi-los através da sua autodeterminação, energia e percepção de controle interno. Esses aspectos corroboram o fato de as pessoas serem capazes de gerar caminhos alternativos para os objetivos que determinaram quando surgem obstáculos ou impedimentos aos inicialmente traçados. 
Não obstante, Filion (1999) apontar que um empreendedor é uma pessoa imaginativa distinguida pela capacidade de estabelecer e alcançar objetivos relata que os empreendedores, apresentam características que propiciam ações mais arrojadas por serem sonhadores e imaginativos, comprometidos com seus negócios e lidam bem com situações adversas e inesperadas. Estas características coadunam com a autoeficácia e com a confiança presentes no modelo do capital psicológico (LUTHANS et al., 2004) por acreditarem na própria capacidade de mobilizar recursos cognitivos para obter recursos específicos. Convergindo com esses pressupostos, Bandura (1997) discute a autoeficácia a partir da crença que o empreendedor tem de sua capacidade para lidar com tarefas desafiadoras, com motivação e esforço no cumprimento de seus objetivos, principalmente quando confrontados com obstáculos (LUTHANS et al., 2004).

Assim, a autoeficácia tem sido e continua a ser uma das variáveis psicológicas fundamental no estudo do comportamento empreendedor, tanto em seu poder preditivo sobre a intenção de criar uma nova empresa (BOYD et al., 1994; LIÑÁN et al., 2009; PIHIE, 2009; ZHAO et al., 2005), e sua capacidade de diferenciar empreendedores de não empreendedores (MARKMAN et al., 2005).

Hisrich et al. (2009) aponta que é frequente os empreendedores tomarem decisões em ambientes altamente inseguros, com altos riscos, intensas pressões de tempo e considerável investimento emocional. Por sua vez, uma das variáveis que compõe o capital psicológico é a resiliência (LUTHANS, 2002a; LUTHANS et al., 2004), cujos indivíduos se mostram capazes de recuperar ou superar possíveis adversidades, incerteza ou falha, e até mesmo de propiciarem mudanças positivas com tarefas que acarretam maior responsabilidade. Na psicologia a resiliência é utilizada para explicar superação de crises e adversidades em indivíduos, grupos e organizações.

Não obstante, Luthans et al. (2004) mencionou várias características como fundamentais para as ações empreendedoras. Lopes et al. (2006) traz o otimismo como o ponto central e sinérgico entre todas as características, por ser dotada de crença que boas coisas acontecem e por dar forças ao empreendedor de romper barreiras, desobstruir obstáculos e seguir adiante com objetivos audaciosos (LUTHANS, 2002b).

\section{CONSIDERAÇÕES FINAIS}

O objetivo desse artigo teórico foi o de propiciar reflexões teóricas e levantar possíveis convergências entre as características do indivíduo empreendedor e o constructo do capital psicológico. As convergências demonstradas entre os pressupostos das teorias podem contribuir para a solidificação dos estudos destes fenômenos, ficando evidente a importância de buscar conhecimentos empíricos desses pressupostos. As pesquisas no campo do empreendedorismo têm procurado testar relações diferentes variáveis em busca de entendimentos que auxiliem tanto na solidificação do processo do empreendedorismo como na clarificação sobre o comportamento que caracteriza um indivíduo como empreendedor. As capacidades psicológicas positivas que formam o capital psicológico são mencionadas na maioria dos trabalhos evidenciando um caminho a ser investigado com maior profundidade. 
As capacidades psicológicas que formam o constructo do capital psicológico, autoeficácia, esperança, otimismo e resiliência apresentam pontos de aproximação com várias características que elegem um indivíduo como empreendedor. O levantamento de pesquisas realizado neste estudo evidencia que estes temas carecem de estudos empíricos, sobretudo no contexto brasileiro, não obstante não serem também suficientes no âmbito internacional para explicar a complexidade deste fenômeno, visando trazer contribuições efetivas e assim, ampliar o conhecimento da área.

\section{REFERÊNCIAS}

APA. American Psychological Association. Dicionário de psicologia da APA. Porto Alegre: Artmed, 2010.

BANDURA, A.. Self-efficacy: the exercise of control. New York: Freeman, 1997.

BARON, R. A.. Cognitive mechanisms in entrepreneurship: why and when entrepreneurs think differently than other people. Journal of Business Venturing, v.13, 1998.

BARON, R. A.; SHANE, M. S. A.. Empreendedorismo: uma visão do processo. São Paulo: Thomson Learning, 2011.

BHIDÉ, A.. Como os empreendedores constroem estratégias que dão certo. Harvard Business Review, Rio de Janeiro, 2002.

BOHNENBERGER, M. C.; SCHMIDT, S.; FREITAS, E. C.. A influência da família na formação empreendedora. In: ENCONTRO ANUAL DE PÓS-GRADUAÇÃO E PESQUISA EM ADMINISTRAÇÃO. Anais. Rio de Janeiro: 2007.

BOYD, N. G.; VOZIKIS, G. S.. The Influence of Self-Efficacy on the Development of Entrepreneurial Intentions and Actions. Entrepreneurship Theory \& Practice, Summer, 1994.

BRANCHER, I. B.; OLIVEIRA, E. M.; RONCON, A.. Comportamento empreendedor: estudo bibliométrico da produção nacional e a influência de referencial teórico internacional. Internext: Revista Eletrônica Negócios Internacionais da ESPM, v.7, n.1, p.166-193, 2012.

BYGRAVE, W. D.. The Entrepreneurial Process. In: BYGRAVE, W. D.; ZACHARAKIS, A.. The Portable MBA in

Entrepreneurship. Hoboken: John Wiley \& Sons, 2004.

DRUCKER, P. F.. Innovation and entrepreneurship: practice and principles. New York: Harper \& Row, 1986.

FALCONE, T.; OSBORNE, S.. Entrepreneurship: a diverse concept in a diverse world. Lisboa: UNL, 2005

FILION, L. J.. Empreendedorismo: Empreendedores e proprietários-gerentes de pequenos negócios. Revista de Administração, São Paulo, v.34, n.2, 1999.

GARAVAN, T.; O'CINNEIDE, B.. Entrepreneurship education and training programs: a review of and evaluation. Journal of European Industrial Training, v.8, n.8, p.3-12, 1994.

HAYEK, M.. Control Beliefs and Positive Psychological Capital: can nascent entrepreneurs discriminate between what can and cannot be controlled?. Journal of Management Research, v.1, 2012.

HISRICH, R. D.; PETERS, M. P.; SHEPHERD, D. A..

Empreendedorismo. 7 ed. Porto Alegre: Bookman, 2007.

HONMA, E. T.. Competências empreendedoras: estudo de casos múltiplos no setor hoteleiro em Curitiba. Dissertação (Mestrado) - Universidade Federal do Paraná, Curitiba, 2007.

IZQUIERDO, E.; BUELENS, M.. Competing models of entrepreneurial intentions: the influence of entrepreneurial self-efficacy and attitudes. International Journal of Entrepreneurship and Small Business, v.13, n.1, 2008.

JAMES, N.; GUDMUNDSSON, A.. Exploring the impact of entrepreneur optimism on the new venture process. In: INTERNATIONAL ENTREPRENEURSHIP RESEARCH EXCHANGE, 8. Anais. Melbourne: Swinburne University of Technology, 2011.

JENSEN, S. M.; LUTHANS, F.. The Relationship Between Entrepreneurs' Psychological Capital and Authentic Leadership Dimensions. Journal of Managerial Issues, v.18, n.2, 2006.

JULIEN, P. A.. Empreendedorismo regional e a economia do conhecimento. São Paulo: Saraiva, 2010.

KIRZNER, I. M.. Competition and entrepreneurship. Chicago: Chicago University Press, 1973.

LIÑÁN, F.; CHEN, Y. W.. Development and cross-cultural application of a specific instrument to measure entrepreneurial intentions. Entrepreneurship Theory and Practice, Estocolmo, v.33, 2009.

LOPES, M. P.; CUNHA, M. P.; PALMA, P. J.. Positive psychological capital: Distinguishing profiles and their impact on organizational climate. Lisboa: Working Paper ISPA, 2006

LUTHANS, F.. Positive organizational behavior: Developing and managing psychological strengths. Academy of Management Executive, v.16, n.1, p.57-75, 2002b.

LUTHANS, F.. The need for and meaning of positive organizational behavior. Journal of Organizational Behavior, v.23, p.695-706, 2002a.

LUTHANS, F.; AVOLIO, B. J.; WALUMBWA, F. O.; LI, W.. The psychological capital of Chinese workers: exploring the 
relationship with performance. Management and

Organization Review, v.1, n.2, p.249-271, 2005.

LUTHANS, F.; YOUSSEF, C. M.. Human, social, and now positive psychological capital management: Investing in people for competitive advantage. Organizational Dynamics, v.33, n.2, 2004.

LUTHANS, F.; YOUSSEF, C.; AVOLIO, B.. Psychological Capital: Developing the Human Competitive Edge. New York: Oxford University Press, 2007.

MARKMAN, G. D.; BARON, R. A.; BALKIN, D. B.. Are perseverance and self-efficacy costless? Assessing entrepreneurs' regretful thinking. Journal of Organizational Behavior, v.26, n.1, 2005.

MCCLELLAND, D. C.. Achievement motivation can be developed. Harvard Business Review, v.43, p.6-25, 1965.

MCCLELLAND, D. C.. Business Drive and National Achievement. Harvard Business Review, p.99-112, 1972.

MCCLELLAND, D. C.. Characteristics of successful entrepreneurs. Framingham: Small Business Administration and the National Center for Research in Vocational Education, 1986.

MORRISON, A.. Entrepreneurship: An international perspective. Oxford: Butterworth-Heinemann, 1998.

$\mathrm{OECH}, \mathrm{R}$. V.. Um toc na cuca: técnicas para quem quer ter mais criatividade na vida. São Paulo: Cultura, 1995.

OGBOR, J.. Mythicising and reification in entrepreneurial discourse: ideology critique of entrepreneurial studies, Journal of Management Studies, v.37, p.605-635, 2000.

PAGE, L. F.; DONOHUE, R.. Positive psychological capital: a preliminary exploration of the construct. Business and Economics, Wellington, v.51, n.4, 2004.
PALMA, P. J.; CUNHA, M. P.; LOPES, M. P.. Comportamento organizacional positivo e empreendedorismo: Uma influência mutuamente vantajosa. Comportamento Organizacional e Gestão, v.12, n.1, 2007.

PIHIE, Z. A. L.. Entrepreneurship as a career choice: An analysis of entrepreneurial Self-Efficacy and intention of university students. European Journal of Social Sciences, v.9, n.2, 2009.

SABBAG, P. Y.. Resiliência competência para enfrentar situações extraordinárias na sua vida profissional. São Paulo: Campus, 2012.

SELIGMAN, M. P.; CSIKSZENTMIHALYI, M.. Positive Psychology: an introduction. American Psychologist, v.55, n.1, p.5-14, 2000.

SNYDER, C. R.. Handbook of Positive Psychology. New York: Oxford University Press, 2002.

STAJKOVIC, A.; LUTHANS, F.. Self-efficacy and work-related performance: A meta-analysis. Psychological Bulletin, v.124, p.240-261, 1998.

TORRES, J. L. N.; WATSON, W.. An Examination of the Relationship of Manager Self-Efficacy to Entrepreneurial Intentions and to Performance in Mexican Small Businesses. Contaduria y Administración, v.58, n.3, p.65-87, 2013.

VRIES, M. F. R. K.. Liderança na empresa: como o comportamento dos líderes afeta a cultura interna. São Paulo: Atlas, 1997.

WEBER, M.. A ética protestante e o espírito do capitalismo. São Paulo: Pioneira, 1989.

ZHAO, H.; SEIBERT, S. E.; HILLS, G. E.. The mediating role of self-efficacy in the development of entrepreneurial intentions. Journal of Applied Psychology, v.90, n.6, p.12651272, 2005. 